\title{
Microbial EC50 Fold Change from Reference
}

National Cancer Institute

\section{Source}

National Cancer Institute. Microbial EC50 Fold Change from Reference. NCI Thesaurus.

Code C139115.

A fold change based on the concentration of a specific drug expected to produce 50

percent inhibition of the population growth or replication of a microbial organism; it is a ratio calculated by the EC50 Subject Result divided by the EC50 Reference Control Result. 